\title{
Species structure of sand fly (Diptera: Psychodidae) fauna in the Brazilian western Amazon
}

\author{
Luiz Herman Soares Gil, Maisa da Silva Araújo/ ${ }^{+}$, Juan Miguel Villalobos, Luis Marcelo Aranha \\ Camargo, Luiz Shozo Ozaki, Cor Jesus Fernandes Fontes, Paulo Eduardo Martins Ribolla, Tony Hiroshi \\ Katsuragawa, Rafael Mesquita Cruz, Alexandre de Almeida e Silva, Luiz Hildebrando Pereira da Silva
}

Instituto de Pesquisa de Patologias Tropicais, Rua da Beira 7671, 78912-000 Porto Velho, RO, Brasil

We surveyed areas of the state of Rondônia in western Amazon for phlebotomine, which are potential vectors of leishmaniasis. A total of 5,998 specimens were captured, resulting in the identification of 48 species within the Lutzomyia (99.98\%) and Brumptomyia (0.02\%) genera. The predominant species was Lutzomyia davisi, followed by Lutzomyia umbratilis, Lutzomyia llanosmartinsi, Lutzomyia c. carrerai, Lutzomyia dendrophyla, Lutzomyia nevesi and Lutzomyia whitmani. All sand flies identified as vectors for cutaneous leishmaniasis in Brazil, i.e., Lu. davisi, Lu. umbratilis, Lu. c. carrerai and Lu. whitmani, were found in the surveyed areas.

Key words: phlebotomine - vectors of leishmaniasis - leishmania - Rondônia

Phlebotomine sand flies (Diptera: Psychodidae) are insects of medical and veterinary importance, as they are responsible for the transmission of various diseases such as bartonellosis, arboviruses and visceral and cutaneous leishmaniasis. Their bites are painful and may also produce allergic manifestations (Forattini 1973, Young \& Duncan 1994). In the Neotropics, they are grouped in three different genera: Brumptomyia (França \& Parrot 1921), Warileya (Hertig 1948) and Lutzomyia (França 1924). Only the last genus includes species of medical importance for the transmission of leishmaniasis in the New World. In the Amazon Region, these insects show a high richness of species (Young \& Duncan 1994) with high indices of local diversity in terra-firme forests (Barrett et al. 1996). Of the more than 400 species of Lutzomyia already identified in Brazil, 122 can be found in the Amazon Region; of these, 25 have anthropophilic behaviour characteristics. The Psychodopygus and Nyssomyia subgenera predominate in many regions of the state of Amazonas (AM) (Ward et al. 1973, Grimaldi et al. 1991, Rangel \& Lainson 2003) and their many species in these regions are demonstrated to be important vectors of cutaneous leishmaniasis in both enzootic and zoonotic cycles.

Cutaneous leishmaniasis is a major public health problem in the state of Rondônia (RO). Data from the Brazilian Ministry of Health shows the region has a high prevalence of cutaneous leishmaniasis with an annual incidence of 115 cases per 100,000 inhabitants. In 1997, there were 1,465 confirmed cases, with increasing num-

Financial support: Tecsolo

+Corresponding author: maisaraujo@gmail.com

Received 23 February 2009

Accepted 7 October 2009 bers in 2002-2004 followed by some reduction in subsequent years. Many species of Leishmania cause disease in humans and the ones found in RO are Leishmania ( Viannia) braziliensis, Leishmania (Viannia) laisonni and Leishmania (Viannia) amazonensis (MS 2007).

Knowledge of phlebotomine diversity, species prevalence, distribution and anthropophilic behaviour, especially in leishmania endemic areas, is necessary to understand the natural history of parasite transmission and to control the disease (Memmot 1991). This study supplies more information on the diversity of the phlebotomine fauna in $\mathrm{RO}$, an endemic state for cutaneous leishmaniasis and identifies the potential vector of the parasite in the region.

\section{MATERIALS AND METHODS}

The climate in RO is characterized by well-marked dry and wet seasons. The average annual temperature is $28.6^{\circ} \mathrm{C}$ and varies from $18-37^{\circ} \mathrm{C}$. Rain occurs mainly between November-April, with much drier weather conditions during the rest of the year (May-August). Sand flies were captured from May-August of 1997 (Figure), with two capture sessions in rural areas of Vilhena, Espigão D'Oeste, Vale do Anari and Porto Velho, three sessions in Nova União and Monte Negro and four sessions in Nova Mamoré and Costa Marques. Four CDC-type light traps were used at each locality from 6pm-6am and one Shannon trap was used from $6 \mathrm{pm}-8 \mathrm{am}$. The CDC light traps were placed on tree canopies about $18 \mathrm{~m}$ high and near the ground about $1 \mathrm{~m}$ high. Captured sand flies were stored in $70 \%$ ethanol and later identified in the laboratory as described by Young and Duncan (1994).

\section{RESULTS AND DISCUSSION}

A total of 5,998 sand fly specimens were captured in eight localities, of which 1,736 were male $(29 \%)$ and 4,262 were female (71\%). A high diversity among the sand flies was observed, with 48 species being identified and distributed as follows: one species of the genus Brumptomyia and 42 of the genus Lutzomyia, divided 


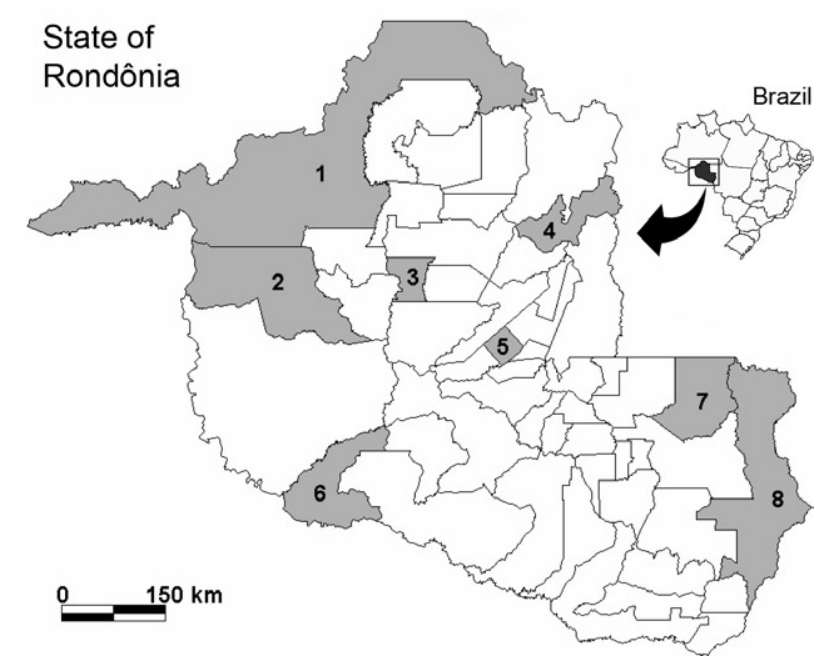

Locations of the eight study areas, municipalities of state of Rondônia. 1: Porto Velho; 2: Nova Mamoré; 3: Monte Negro; 4: Vale do Anari; 5: Nova União; 6: Costa Marques; 7: Espigão do Oeste; 8: Vilhena. Fonte: SEDAM.

into eight subgenera and three groups (Table). The subgenus Psychodopygus represented $59.5 \%$ of the total specimens captured and the subgenus Nyssomyia represented $23.7 \%$. These two subgenera are indeed described as the most predominant in the Amazon Region and are more prevalent there than in any other region of the Americas (Ward et al. 1973, Silva et al. 2007). Species considered important vectors for cutaneous leishmaniasis, in both enzootic and zoonotic cycles, are classified into these two subgenera (Grimaldi et al. 1991, Gil et al. 2003).

Some of the species found in this survey are being described for the first time in the region. Amongst the new species recorded are Lutzomyia brachyphalla (Mangabeira 1941), Lutzomyia castanheirai (Damasceno, Causey \& Arouck 1945), Lutzomyia readyi Ryan 1986 and Lutzomyia spathotrichia Martins, Falcão \& Silva 1963. These species, however, are not related to the transmission of Leishmania (CIPA 1999).

The following 15 species have been previously reported in RO but were not observed in the present study: Lutzomyia longipalpis (Lutz \& Neiva 1912), Brumptomyia cunhai (Mangabeira 1942), Brumptomyia travassosi (Mangabeira 1942), Lutzomyia b. barrettoi (Mangabeira 1942), Lutzomyia brachipyga (Mangabeira 1942), evandroi (Costa Lima \& Antunes 1936), Lutzomyia inpai Young \& Arias 1977, Lutzomyia longipennis (Barretto 1946), Lutzomyia migonei (França 1920), Lutzomyia oswaldoi (Mangabeira 1942), Lutzomyia peresi (Mangabeira 1942), Lutzomyia shannoni (Dyar 1929), Lutzomyia anduzei (Rozeboom 1942), Lutzomyia brasiliensis (Costa Lima 1932) and Lutzomyia williamsi (Damasceno, Causey \& Arouck 1945). Lu. longipalpis, the main vector of American visceral leishmaniasis, was previously reported by Gil et al. (2003), suggesting a risk of endemic visceral leishmaniasis in the state. This species is in fact rare and in the previous survey, it was only captured during the rainy season, between August-
November. The present study was performed from MayAugust, when rainfall is at minimum. Barros et al. (2000) reported that, in the neighbour state of Maranhão (MA), Lu. longipalpis density peaks in the months of February and March and gradually lowers until disappearing in the months of November/December.

The Lutzomyia davisi (Root 1934) (32.8\%), Lutzomyia umbratilis Ward \& Fraiha 1977 (10.4\%), Lutzomyia llanosmartinsi (Fraiha \& Ward 1980) (7.5\%), Lutzomyia c. carrerai (Barretto 1946) (7.2\%), Lutzomyia dendrophyla (Mangabeira 1942) (7.2\%), Lutzomyia nevesi (Damasceno \& Arouck 1956) (6.9\%) and Lutzomyia whitmani(Antunes \& Coutinho 1939) $(6.8 \%)$ species represented $78.8 \%$ of the specimens in the present survey (Table). In the previous survey, the Lutzomyia richardwardi (Ward \& Ready 1975), Lu. umbratilis and $L u$. c. carrerai species were shown to be prevalent in the Samuel Ecological Station in RO (Azevedo et al. 1993). Lutzomyia h. hirsuta (Mangabeira 1942), Lu. davisi, Lu. whitmani and Lu. c. carreirai were shown to be prevalent in some counties of the state, while Lu. umbratilis, Lu. llanosmartinsi, Lu. dendrophyla and Lu. nevesi had no such prevalence (Gil et al. 2003). Variations in the pattern of species observed during different surveys are common and can be due to the length of capture time, seasonal variation or environmental changes (Cabanillas \& Castellón 1999, Castellón et al. 2000, Azevedo et al. 2002).

Lu. davisi and Lu. whitmani have broad distribution in the Amazon Region (Rebêlo et al. 1996, Silva et al. 2007) and are demonstrated to have anthropophilic habits (Luz et al. 2000, Gil et al. 2003). In Mato Grosso (MT) and AM, Lu. davisi was recorded less often and was more arboreal than terrestrial (Azevedo et al. 2002, Dias-Lima et al. 2002). The predominance of $L u$. whitmani has been recorded in drier seasons in Mato Grosso do Sul (Galati et al. 2006). However, this species has been observed with the highest frequency in the rainy month of March in RO (Gil et al. 2003), although adult forms can be found in any month of the year (Luz et al. 2000). In the state of Acre it was one of the most prevalent species and was considered one of the potential Leishmania vectors in the Bujari municipality and Rio Branco municipality (Azevedo et al. 2008). The high density of Lu. whitmani may also be associated with modifications in the original cover vegetation and better adaptation to new environmental conditions (Azevedo et al. 2002). It is found in all areas where cutaneous leishmaniasis is recorded (Luz et al. 2000) and previous studies have connected this species with the transmission of Leishmania (Viannia) shawi in the Amazon Region (Lainson \& Shaw 1998, Rangel \& Lainson 2003, Costa et al. 2007).

$L u$. umbratilis is found in MA, with greater frequency in wild areas (Rebêlo et al. 1999). In the primary forests of the central Amazonia, it is the species with the greatest presence in tree canopies (Dias-Lima et al. 2002, Azevedo et al. 2008). However, stratification studies show that the density of Lu. umbratilis is as high in the canopy as it is on the ground, where it can feed during the night on the arboreal sloth Choloepus 


\section{TABLE}

Sand flies captured in the state of Rondônia from May-August 1997 with Shannon and CDC light traps

\begin{tabular}{|c|c|c|c|c|}
\hline Species & Female & Male & Total & $\%$ \\
\hline Brumptomyia avellari & - & 1 & 1 & 0.02 \\
\hline Lutzomyia aragaoi (Group Aragaoi) & - & 1 & 1 & 0.02 \\
\hline Lutzomyia (Evandromyia) brachyphalla & - & 1 & 1 & 0.02 \\
\hline Lutzomyia (Lutzomyia) carvalhoi & 1 & - & 1 & 0.02 \\
\hline Lutzomyia (Lutzomyia) evangelistai & 2 & 2 & 4 & 0.07 \\
\hline Lutzomyia (Lutzomyia) gomezi & 11 & 5 & 16 & 0.3 \\
\hline Lutzomyia (Lutzomyia) spathotrichia & 10 & - & 10 & 0.2 \\
\hline Lutzomyia nevesi (Group Verrucarum) & 313 & 101 & 414 & 6.9 \\
\hline Lutzomyia (Nyssomyia) antunesi & 3 & 7 & 10 & 0.2 \\
\hline Lutzomyia (Nyssomyia) flaviscutellata & 23 & 23 & 46 & 0.8 \\
\hline Lutzomyia (Nyssomyia) infraspinosa & 3 & 2 & 5 & 0.08 \\
\hline Lutzomyia (Nyssomyia) richardwardi & 119 & 2 & 121 & 2 \\
\hline Lutzomyia (Nyssomyia) shawi & 9 & 1 & 10 & 0.2 \\
\hline Lutzomyia (Nyssomyia) umbratilis & 441 & 184 & 625 & 10.4 \\
\hline Lutzomyia (Nyssomyia) y.yuilli & 169 & 32 & 201 & 3.3 \\
\hline Lutzomyia (Nyssomyia) whitmani & 153 & 254 & 407 & 6.8 \\
\hline Lutzomyia (Sciopemyia) sordellii & 30 & 18 & 48 & 0.8 \\
\hline Lutzomyia (Sciopemyia) servulolimai & - & 2 & 2 & 0.03 \\
\hline Lutzomyia (Pintomyia) damascenoi & 1 & - & 1 & 0.02 \\
\hline Lutzomyia (Psathyromyia) campbelli & - & 1 & 1 & 0.02 \\
\hline Lutzomyia (Psathyromyia) dendrophyla & 114 & 317 & 431 & 7.2 \\
\hline Lutzomyia (Psathyromyia) lutziana & - & 2 & 2 & 0.03 \\
\hline Lutzomyia (Psathyromyia) punctigeniculata & - & 1 & 1 & 0.02 \\
\hline Lutzomyia (Psathyromyia) scaffi & - & 6 & 6 & 0.1 \\
\hline Lutzomyia (Psychodopygus) amazonensis & 25 & 1 & 26 & 0.4 \\
\hline Lutzomyia (Psychodopygus) ayrozai & 69 & 2 & 71 & 1.2 \\
\hline Lutzomyia (Psychodopygus) bispinosa & 2 & - & 2 & 0.03 \\
\hline Lutzomyia (Psychodopygus) c. carrerai & 381 & 53 & 434 & 7.2 \\
\hline Lutzomyia (Psychodopygus) claustrei & 8 & 5 & 13 & 0.2 \\
\hline Lutzomyia (Psychodopygus) chagasi & 3 & 19 & 22 & 0.4 \\
\hline Lutzomyia (Psychodopygus) complexa & 35 & 22 & 57 & 1 \\
\hline Lutzomyia (Psychodopygus) corossoniensis & 24 & - & 24 & 0.4 \\
\hline Lutzomyia (Psychodopygus) davisi & 1,450 & 516 & 1,966 & 32.8 \\
\hline Lutzomyia (Psychodopygus) geniculatus & 3 & 4 & 7 & 0.1 \\
\hline Lutzomyia (Psychodopygus) h. hirsuta & 54 & 40 & 94 & 1.6 \\
\hline Lutzomyia (Psychodopygus) lainsoni & 21 & 13 & 34 & 0.6 \\
\hline Lutzomyia (Psychodopygus) llanosmartinsi & 391 & 60 & 451 & 7.5 \\
\hline Lutzomyia (Psychodopygus) paraensis & 4 & - & 4 & 0.07 \\
\hline Lutzomyia (Psychodopygus) wellcomei/complexus ${ }^{a}$ & 363 & - & 363 & 6.0 \\
\hline Lutzomyia runoides (Group Aragaoi) & - & 1 & 1 & 0.02 \\
\hline Lutzomyia saulensis (Group Saulensis) & 1 & - & 1 & 0.02 \\
\hline Lutzomyia (Trichophoromyia) castanheirai & 1 & - & 1 & 0.02 \\
\hline Lutzomyia (Trichophoromyia) dasypodogeton & 2 & 8 & 10 & 0.2 \\
\hline Lutzomyia (Trichophoromyia) auraensis & 1 & 6 & 7 & 0.01 \\
\hline Lutzomyia (Trichophoromyia) octavioi & 2 & 1 & 3 & 0.05 \\
\hline Lutzomyia (Trichophoromyia) readyi & - & 1 & 1 & 0.02 \\
\hline Lutzomyia (Trichophoromyia) ubiquitalis & 19 & 19 & 38 & 0.6 \\
\hline Lutzomyia wilsoni (Group Saulensis) & 1 & 2 & 3 & 0.05 \\
\hline Total & 4,262 & 1,736 & 5,998 & 100 \\
\hline
\end{tabular}

$a$ : because there are no clear morphological distinction between the females of $L u$. complexus and $L u$. wellcomei, they are included together. 
didactylus and on the terrestrial Tamandua tetradacty$l a$, both reservoirs of leishmaniasis. Lu. umbratilis can also feed on humans in the first hours of daylight and at dusk when disturbed (Lainson 1983, Ready et al. 1986). In RO, Lu. umbratilis has been shown to be at a low density and is not considered a potential vector of leishmaniasis in some counties (Gil et al. 2003). However, in the Samuel Ecological Station, it was the second most prevalent species (Azevedo et al. 1993)

Worthy of special attention are the species Lu. davisi, Lu. umbratilis, Lu. c. carrerai and Lu. whitmani, which are considered potential vectors for cutaneous leishmaniasis and represent $57.2 \%$ of the specimens captured in the present survey. $L u$. davisi is recognized as a potential vector of Le. (V.) braziliensis and Leishmania (Viannia) naiffi and specimens have been found in the wild that are infected with both pathogens (Grimaldi et al. 1991, Gil et al. 2003). Lu. c. carrerai is also recognized as a vector of Le. (V.) braziliensis in Brazil and Bolivia (Le Pont et al. 1988, Grimaldi et al. 1989). Lu. whitmani has been regarded as one of the most important vectors of American cutaneous leishmaniasis in both peridomiciliar and forest environments (Luz et al. 2000, Rangel \& Lainson 2003, Leonardo \& Rebêlo 2004). This species was found infected with Le. (V.) braziliensis in the states of Bahia, Paraná and Ceará (Luz et al. 2000). It is also considered a vector of $L e$. (V.) shawi which has various mammals as reservoirs such as primates (Cebus paella), bats (Chiropotes satanus), sloths (Choloepus didactylus, Bradypus tridactylus) and coati (Nasua nasua) (Rebêlo et al. 1996). This sand fly species maintains a more sylvatic cycle, as shown in various studies (Queiroz et al. 1994, Peterson \& Shaw 2003).

Lu. umbratilis has great significance as a vector of Leishmania (Viannia) guyanensis in Northern Brazil and the Guianas (Lainson 1983, Ready et al. 1985, Rebêlo et al. 1999, Dias-Limas et al. 2002). Azevedo et al. (2002) suggest the existence of a species complex because, according to Lainson (1988), Lu. umbratilis only transmits Le. (V.) guyanensis in the north of the Amazon River while in the north of MT. It may also be that genetically heterogeneous populations could be associated with different cycles of leishmaniasis transmission in Brazil (Lainson 1988).

In conclusion, a predominant presence of $\mathrm{Lu}$. davisi and the observed increase in the number of Lu. umbratilis flies suggest continuous transmission activity of leishmaniasis in the surveyed areas. Lu. davisi, a potential vector of zoonotic cutaneous leishmaniasis, continues to be a threat in the transmission of the disease in the region, as previously observed (Gil et al. 2003). The predominance of some species in anthropic environments is a relevant factor in leishmaniasis transmission, as shown in other studies regarding the phlebotomine fauna (Gomes et al. 1989, Mayo et al. 1998). Because of the diversity of sand fly species and the fluctuations in the predominance that can occur with any sand fly species that is a potential vector of American cutaneous leishmaniasis, we emphasize the importance of improving and further extending the entomological vigilance of the phlebotomine fauna in the region.

\section{ACKNOWLEDGEMENTS}

To the Government of Rondônia, Tecnosolo, DVH-Consult and FUNASA, for their cooperation during the field work for the development of this research.

\section{REFERENCES}

Azevedo ACR, Costa SM, Pinto MCG, Souza JL, Cruz HC, Vida J, Range EF 2008. Studies on the sandfly fauna (Diptera: Psychodidae: Phlebotominae) from transmission areas of American cutaneous leishmaniasis in state of Acre, Brazil. Mem Inst Oswaldo Cruz 103: 760-767.

Azevedo ACR, Luz SLB, Vieira ML, Rangel EF 1993. Studies on the sandfly fauna of Samuel Ecological Station Porto Velho nunicipality, Rondônia state, Brazil. Mem Inst Oswaldo Cruz 88: 509-512.

Azevedo ACR, Souza NA, Meneses CR, Costa WA, Costa SM, Lima JB, Rangel EF 2002. Ecology of sand flies (Diptera: Psychodidae: Phlebotominae) in the north of the state of Mato Grosso, Brazil. Mem Inst Oswaldo Cruz 97: 459-464.

Barrett TV, Freitas RA, Albuquerque MIC, Guerrero JHC 1996. Report on a collection of Lutzomyia sandflies (Diptera: Psychodidae) from the middle Solimões (Amazonas, Brazil). Mem Inst Oswaldo Cruz 91: 27-35.

Barros VL, Rebelo JM, Silva FS 2000. Flebotomíneos (Diptera, Psychodidae) de capoeira do município do Paço do Lumiar, estado do Maranhão, Brasil: área de transmissão de leishmaniose. Cad Saude Publica 16: 265-270.

Cabanillas MRS, Castellon EG 1999. Distribution of sandflies (Diptera: Psychodidae) on tree-trunks in a non-flooded area of the Ducke Forest Reserve, Manaus, AM, Brazil. Mem Inst Oswaldo Cruz 94: 289-296.

Castellón EG, Fé NF, Buhrnheim PF, Fé FA 2000. Flebotomíneos (Diptera: Psychodidae) na Amazônia. II. Listagem das espécies coletadas na Bacia Petrolífera no Rio Urucu, Amazonas, Brasil, utilizando diferentes armadilhas e iscas. Rev Bras Zool 17: 455-462.

Cipa Group 1999 [homepage on the internet]. Paris: Computer-aided identification of phlebotomine sandflies of America. Site hosted by Université Pierre et Marie Curie [updated 1999]. Available from: www.cipa.snv.jussieu.fr/.

Costa SM, Cechinel M, Bandeira V, Zannuncio JC, Lainson R, Rangel EF 2007. Lutzomyia (Nyssomyia) whitmani s.l. (Antunes \& Coutinho 1939) (Diptera: Psychodidae: Phlebotominae): geographical distribution and the epidemiology of American cutaneous leishmaniasis in Brazil. Mini-review. Mem Inst Oswaldo Cruz 102: 149-153.

Dias-Lima A, Bermudez EC, Medeiros JF, Sherlock I 2002. Estratificação vertical da fauna de flebótomos (Díptera: Psychodidae) numa floresta primária de terra firme da Amazônia Central, estado do Amazonas, Brasil. Cad Saude Publica 18: 823-32.

Forattini O 1973. Entomologia médica. Psychodidae. Phlebotominae. Leishmanioses. Bartonelose, Editora Edgar Blücher Ltda. e Editora da Universidade de São Paulo, São Paulo, 658 pp.

Galati EAB, Nunes VL, Boggiani PC, Dorval MEC, Cristaldo G, Rocha HC, Oshiro ET, Damasceno-Júnior GA 2006. Phlebotomines (Diptera: Psychodidae) in forested areas of the Serra da Bodoquena, state of Mato Grosso do Sul, Brazil. Mem Inst Oswaldo Cruz 101: 175-193.

Gil LHS, Basano SA, Souza AA, Silva, MGS, Barata I, Ishikawa ED, Camargo LMA, Shaw JJ 2003. Recent observations on the sand fly (Diptera: Psychodidae) fauna of the state of Rondônia, western Amazônia, Brazil: the importance of Psychdopygus davisi as a vector of zoonotic cutaneous leishmaniasis. Mem Inst Oswaldo Cruz 98: 751-755. 
Gomes AC, Barata JMS, Rocha, Silva EO, Galati EAB 1989. Aspectos ecológicos da leishmaniose tegumentar americana. 6. Fauna flebotomínea antropófila de matas residuais situadas na região centro-nordeste do Estado de São Paulo, Brasil. Rev Soc Bras Med Trop 31: 32-39.

Grimaldi G Jr, Momen H, Naiff RD, McMahon-Pratt D, Barrett TV 1991. Characterization and classification of leishmanial parasites from humans, wild mammals and sand flies in the Amazon Region of Brazil. Am J Trop Med Hyg 44: 645-661.

Grimaldi G Jr, Tesh RB, Mcmahon-Pratt D 1989. A review of the geographic distribution and epidemiology of leishmaniasis in the New World. Am J Trop Med Hyg 41: 687-725.

Lainson R 1983. The American leishmaniasis: some observations on their ecology and epidemiology. Trans R Soc Trop Med Hyg 77: $569-596$

Lainson R 1988. Ecological interactions in the transmission of the leishmaniasis. Philos Trans R Soc Lond Serie B 321: 389-404.

Lainson R, Shaw JJ 1998. New Word leishmaniasis the neotropical Leishmania species. In A Ballows, M Sussman (eds.), Microbiology and microbial infections, L Topley and Wilson's Collier, London, p. 241-266.

Leonardo FS, Rebêlo JMM 2004. A periurbanização de Lutzomyia whitmani em área de foco de leishmaniose cutânea, no estado do Maranhão, Brasil. Rev Soc Bras Med Trop 37: 282-284.

Le Pont F, Breniere RS, Mouchet J, Desjeux P 1988. Leishmaniose en Bolivie. III. Psychodopygus carrerai carrerai (Barretto, 1946) nouveau vecteur de Leishmania braziliensis braziliensis en milieu sylvatique de région subandine basse. C R Acad Sci III 307: 279-282.

Luz E, Membrive N, Castro EA, Dereure J, Pratlong F, Dedet JA, Pandey A, Thomaz-Soccol V 2000. Lutzomyia whitmani (Diptera: Psychodidae) as vector of Leishmania ( $V$. braziliensis in Paraná state, Southern Brazil. Ann Trop Med Parasitol 94: 623-631.

Mayo RC, Casanova C, Mascarini LM, Pignatti MG, Rangel O, Galati EAB, Wanderley DMV, Corrêa FMA 1998. Flebotomíneos (Díptera: Psychodidae) de área de transmissão de leishmaniose tegumentar americana, no município de Itupeva, região sudeste do estado de São Paulo, Brasil. Rev Soc Bras Med Trop 31: 339-345.

Memmott J 1991. Sandfly distribution and abundance in a tropical rain forest. J Med Entomol 5: 403-411.
MS - Ministério da Saúde 2007. Secretaria de Vigilância Epidemiológica em Saúde. Available from: www.portal.saude.gov.br.

Peterson AT, Shaw J 2003. Lutzomyia vectors for cutaneous leishmaniasis in Southern Brazil: ecological niche models, predicted geographic distributions and climate change effects. Int J Parasitol 33: 919-931.

Queiroz RG, Vasconcelos IA, Vasconcelos AW, Pessoa FA, de Sousa RN, David JR 1994. Cutaneous leishmaniasis in Ceará state in Northeastern Brazil: incrimination of Lutzomyia whitmani (Diptera: Psychodidae) as a vector of Leishmania braziliensis in Baturité municipality. Am J Trop Med Hyg 50: 693-698.

Rangel EF, Lainson R 2003. Flebotomíneos do Brasil, Fiocruz, Rio de Janeiro, $368 \mathrm{pp}$.

Ready PD, Arias JR, Freitas RA 1985. A pilot to control Lutzomyia umbratilis (Diptera: Psychodidae), the major vector of Leishmania brasiliensis guyanensis, in a peri-urban rainforest of Manaus, Amazonas state, Brazil. Mem Inst Oswaldo Cruz 80: 27-36.

Ready PD, Lainson R, Shaw JJ, Ward RD 1986. The ecology of Lutzomyia umbratilis Ward \& Fraiha (Diptera: Psychodidae), the major vector to man of Leishmania braziliensis guyanensis in northeasther Amazônia, Brazil. Bull Ent Res 76: 21-40.

Rebêlo JMM, Araújo JAC, Carvalho ML, Barros VLL, Silva FS, Oliveira ST 1999. Flebotómos (Diptera: Phlebotominae) da Ilha de São Luis, zona do Golfão Maranhense, Brasil. Rev Soc Bras Med Trop 32: 247-253.

Rebêlo JMM, Mendes WA, Costa JML, Cavaleiro N 1996. Lista preliminar das espécies do gênero Lutzomyia França 1924 (Psychodidae: Phlebotominae) do estado do Maranhão, Brasil. Cad Saude Publica 12: 545-549.

Silva DF, Freitas RA, Franco AMR 2007. Diversidade e abundância de flebotomíneos do gênero Lutzomyia (Diptera: Psychodidae) em áreas de mata do nordeste de Manacapuru, AM. Neotrop Entomol 36: 138-144.

Ward RD, Shaw JJ, Lainson R, Fraiha H 1973. Leishmaniasis in Brazil: VIII. Observations on the phlebotomine fauna of an area of highly endemic cutaneous leishmaniasis in the Serra dos Carajás, Pará state. Trans R Soc Trop Med Hyg 67: 174-183.

Young DG, Duncan MA 1994. Guide to the identification and geographic distribution of Lutzomyia sand flies in Mexico, the West Indies, Central and South America (Diptera: Psychodidae), Memoirs of the American Entomological Institute 54, Associated Publishers, American Entomological Institute, Gainesville, 881 pp. 